\title{
How is a food bank managed? Different profiles in Spain
}

\author{
Pilar L. González-Torre ${ }^{1} \cdot$ Jorge Coque $^{1}$
}

Accepted: 1 February 2015/Published online: 26 March 2015

(C) The Author(s) 2015. This article is published with open access at Springerlink.com

\begin{abstract}
Within the current economic situation, poverty indexes in developed countries are becoming more and more alarming. This makes the role of food banks very relevant, and in addition contributes towards reducing the problem of food waste. Motivated by the social importance of these nonprofit organizations, this paper analyzes the impact of food banks on the supply chains to which they belong. Differences in the functioning of these supply chains are highlighted attending to the relations induced by the food banks. First, the international research background for this topic is summarized; then, the results of an empirical study in Spain are presented. Data were collected through surveys and analyzed using cluster methodology. Two different types of food bank were identified. These are described, characterized, and compared in terms of efficacy and efficiency.
\end{abstract}

Keywords Food bank - Non-profit organizations - Spain

\begin{tabular}{|c|c|}
\hline \multicolumn{2}{|c|}{ Abbreviations } \\
\hline \multicolumn{2}{|c|}{ EU European Unio } \\
\hline FEBA & Fédération Européenne des Banques \\
\hline & $\begin{array}{l}\text { Alimentaires (European Federation of Food } \\
\text { Banks) }\end{array}$ \\
\hline FESBAL & $\begin{array}{l}\text { Federación Española de Bancos de Alimentos } \\
\text { (Spanish Federation of Food Banks) }\end{array}$ \\
\hline USA & United States of America \\
\hline
\end{tabular}

Pilar L. González-Torre

pilargt@uniovi.es

Jorge Coque

coque@uniovi.es

1 Department of Business Administration, University of Oviedo, Viesques Campus, Gijón, Spain

\section{Introduction}

Extreme poverty, defined as the lack of capacity to have the necessary resources to cover the minimum basic human requirements for living, is expected by 2015 to be 883 million people (United Nations 2011, p. 4). In Spain in particular, $21.6 \%$ of the population (more than 10 million people out of the 46.5 million inhabitants, according to INE 2014) is considered "poor" as they have annual incomes lower than 7040 euros (INE 2013), and these figures worsen year by year.

This poverty increase is particularly worrying when considered in parallel with the problem of food waste in developed countries (Pothukuchi and Kaufman 1999; Hodges et al. 2011). Food is a basic human right, together with water, education, peace, and health care (McIntyre 2003). And "if food is a social good, then we should ask how to make nutritious food available to all people irrespective of their social and political location" (Dixon 2014, p. 184). The global food system, however, generates high quantities of waste (Godfray et al. 2010), as both packaging and the food itself. Almost one-third of the food produced annually for human consumption worldwide (approximately 1300 million tons) is wasted (FAO 2011).

The food waste problem is even higher in developed countries, caused especially by retailers and end consumers, who discard still eatable food (Kantor et al. 1997). Food waste is very diverse: raw food, cooked dishes, precooked food, including also food discarded before and after cooking at home, as well as products discarded in the manufacturing, distribution, service, and sale processes (Mena et al. 2011).

The reasons for such waste are equally diverse (Alexander and Smaje 2008): wrongly labelled non-perishable products, cancelled orders, ends of line (the last few 
units of a product on store shelves that are retired for selling), finished promotions, damaged products but still valid for consumption, or wrong packaging. Other meaningful reasons are seasonal orders, order quantity excess, development or test of new products, limited time allowed on shelves, unexpected events, or low quality control (Alexandre and Smaje 2008).

In this context, food banks could be the key to reducing famine by decreasing the sources of food waste. For that reason we set the following research question: Can a specific way be identified of driving food banks' supply chains whose success features might then inspire improvements in the rest? Our interest in this is founded on the fact that food banks have received very little attention in both the academic and practitioner literature on logistics. This research analyzes food waste management in terms of available resources (human, material, and finance) in food banks, and food banks' relationships with their donors and beneficiaries. Such information is used to identify different types or groups of food banks, demanding different and specific improvement measures.

After having identified that the literature about food banks' management and logistics is scarce, the interest of the study comes from the innovative idea of combining the social purposes of non-profit organizations with a traditional topic of business management-the relationship among different members of their supply chain. This means that this research covers a clear gap in the literature by studying food banks from the classical point of view of business management (which we do not believe has ever been applied to this aim), their position in the supply chain in which they are integrated, and their relationships upstream and downstream.

After this section, we define the concept of food banks, highlighting their evolution over time and showing an international panorama. Then the text explains the methodology used in the research, and presents and discusses the results; finally, the last section summarizes the main conclusions.

\section{Food banks}

Food banks are defined as non-profit organizations based on volunteering, whose purpose is to recover food excesses in our society and redistribute them among needy persons, avoiding any food waste or misuse (Starkey et al. 1998, 1999). Various and different academic approaches to the concept of food banks can be found. Among the more recent definitions are those of Martins et al. (2011) who understand that a food bank is a non-profit organization of social solidarity that distributes food through a wide variety of non-profit institutions of social solidarity which feed low-income people; or Handforth et al. (2013) who think that a food bank serves as a center for collecting donations of tinned, fresh, and frozen foods, and drinks. The operating scope of these entities is mainly focused in developed countries, although there are organizations in Third World countries executing similar activities (Schneider 2013).

Food banks have different areas of activity. On the one hand, there are programs to identify food excess sources and food companies that could contribute with donations, for later distribution through non-profit organizations. On the other hand, there are awareness campaigns that include volunteer recruitment and food collection. In most cases, food banks are not responsible for the final distribution of the food to the needy population; rather they distribute it among different, officially known, charitable institutions with non-profit purposes, which have direct contact with the needy population (Berner and O'Brien 2004). Valid food for consumption but not marketable, that would have been destroyed, is delivered in this way to the most needy people. In other words, food banks have the commitment to maintain a well-driven chain, building the bridge between on the one hand food excess and on the other, human need. In fact, the aim of a food bank is giving value to food that otherwise would be considered as waste and therefore thrown away. Part of the waste food along the food supply chain should not be sent directly to landfill because it is safe and nutritious for human consumption and therefore ought to be recovered by a food bank.

The first food bank was created in 1966: St. Mary's Food Bank, in Phoenix, Arizona, USA. It was founded by John Van Engel, a retired man who participated in the collection of fruit and vegetables organized by a helping institution (Cotugna and Beebe 2002). John heard a mother, whose husband was in prison, explaining that she was able to feed her nine sons by collecting the food that had fallen down to the ground when trucks downloaded at a supermarket. This inspired Van Engel, who decided to promote the first volunteering bank. The idea was soon imitated all over the country and many agricultural and food companies joined the initiative. In Europe, the first food bank was created in Paris in 1984. The first Spanish food bank, however, would not be created until 1987, in Barcelona (FESBAL 2014).

Despite the common goal of nurturing the most needy, food banks are adapted to the environment in which they operate and are the result of specific historical processes. Table 1 summarizes the main characteristics of food banks in three continents showing where there are important differences, particularly in terms of user profile and network size. For example, in Canada there are many food banks, every one of which has a smaller coverage than the USA or European ones.

Although the first food bank in Spain was founded later than in the USA, Spanish food banks have now been 
Table 1 Geographical differences of food banks in various countries

\begin{tabular}{|c|c|c|c|c|c|}
\hline Country & USA & Canada & South Africa & $\begin{array}{l}\text { United } \\
\text { Kingdom }\end{array}$ & Spain \\
\hline Donation type & $\begin{array}{l}\text { Food and } \\
\text { money }\end{array}$ & Food and money & Only food & Only food & Only food \\
\hline Start of activity & 1966 & 1981 & 2009 & 1986 & 1987 \\
\hline Donors & $\begin{array}{l}\text { Private and } \\
\text { governmental }\end{array}$ & $\begin{array}{l}\text { Private (people or } \\
\text { organization) }\end{array}$ & All types of organizations & $\begin{array}{l}\text { Private and } \\
\text { governmental }\end{array}$ & $\begin{array}{l}\text { Private and } \\
\text { governmental }\end{array}$ \\
\hline $\begin{array}{l}\text { Funding by } \\
\text { government }\end{array}$ & State and local & Local & State & Not applicable & Not applicable \\
\hline Main users & $\begin{array}{l}\text { Low-income } \\
\text { families }\end{array}$ & $\begin{array}{l}\text { Children and people with } \\
\text { unhealthy diets }\end{array}$ & $\begin{array}{l}\text { Young and adult homeless } \\
\text { and/or malnourished }\end{array}$ & $\begin{array}{l}\text { Low-income } \\
\text { families }\end{array}$ & Low-income families \\
\hline $\begin{array}{l}\text { Total number of } \\
\text { food banks }\end{array}$ & $>200$ & $<500$ & 5 & 250 & 55 \\
\hline $\begin{array}{l}\text { Total number of } \\
\text { people served }\end{array}$ & $>37,000,000$ & $>800,000$ & $>300,000$ & $>120,000$ & $>1,000,000$ \\
\hline $\begin{array}{l}\text { Network or } \\
\text { association }\end{array}$ & $\begin{array}{l}\text { Feeding } \\
\text { America }\end{array}$ & Food Banks Canada & Foodbank South Africa & $\begin{array}{l}\text { FEBA; The } \\
\text { Trussell Trust }\end{array}$ & $\begin{array}{l}\text { FEBA; FESBAL } \\
\text { (Federación } \\
\text { Española de Bancos } \\
\text { de Alimentos) }\end{array}$ \\
\hline
\end{tabular}

Based on Yadlowski and Thériault (1998), Nichols-Casebolt and Morris (2001), Irwin et al. (2007), Warshawsky (2011), Feeding America (2013), Food Banks Canada (2014), Foodbank South Africa (2013), The Trussell Trust (2013), Lambie-Mumford (2013), FEBA (2014), FESBAL (2014)

working for nearly 30 years. Table 2 gives an idea of the relative importance of the European and Spanish food banks, where it can be seen that although the percentage of food recovered is very little, Spain recovers nearly three times the rest of the continent. Moreover, Spanish food banks provide for nearly one million beneficiaries, i.e. $2 \%$ of the whole population, or $12 \%$ of the population at risk of poverty (INE 2014).

The activity of a food bank depends on its suppliers (food companies and other donators), which affects the quantity of food obtained that their clients (the distributing organizations) regard as enough to satisfy the needs. It actually acts as a wholesaler, although the food bank is driven by the availability of donated supplies-precisely the opposite of a conventional supply chain. Management of food banks has become additionally complex due to the manipulation of perishable products in many cases, which are subject to losses of quality and quantity (Rajan et al. 1992; Cai et al. 2013).

Figure 1 shows the different parts of the standard supply chain for a food bank in a developed country and its position, which is similar to a wholesaler, within this chain. This supply chain has another particularity: it is partially integrated by non-profit organizations, which rely on volunteer labor to achieve a social objective (Larson and McLachlin 2011).

Entities that collaborate with food banks are food producers, distributors, shopping malls, wholesalers, warehouses, retailers, transportation companies, financial entities, advertising and communication agencies, public institutions, and different types of national and international organizations. The entities managing the food banks can obtain food either from normal operations or as an output of different governmental help programs. The procedures and organizations involved are different in each case. The operation of the food bank starts once the food has been collected. Food is then classified by volunteers; the beneficiaries are usually phoned to arrange for collection while the food is preserved for later distribution.

Food banks focus their efforts on helping the communities most affected by poverty and famine or malnutrition. Among the various beneficiaries are the following: soup

Table 2 Food recovered by the food banks in the whole European Union and in Spain

\begin{tabular}{llll}
\hline & Total wasted food & Food recovered by food banks \\
\cline { 3 - 4 } & Tons $\times 1000$ & Tons $\times 1000$ & 0.4 \\
European Union & 89,000 & 400 & 107.5 \\
Spain & 7700 & 1.4 \\
\hline
\end{tabular}

Based on FEBA (2014), Magrama (2013), and authors' own survey of the Spanish food banks 
Fig. 1 Position of food banks in a typical supply chain

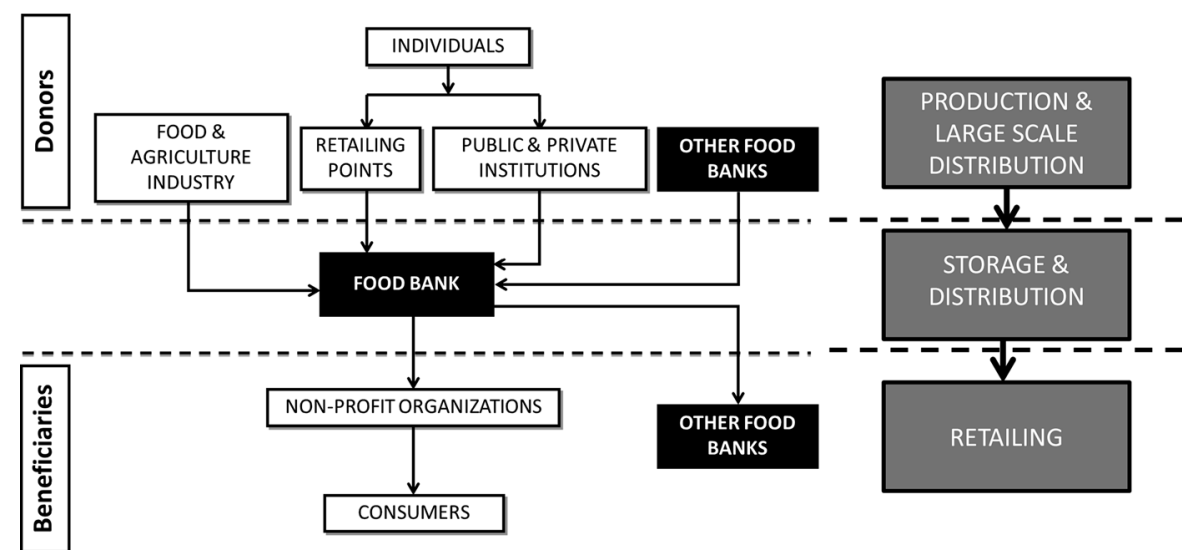

kitchens, hostels for the homeless, family associations, children's associations, youth associations, addiction rehabilitation associations, religious residential centers, labor unions, etc. With regard to social purposes, coordination of the supply chain becomes more complex (Egri and Váncza 2013), due to the intermittent relationship with the suppliers and the difficulties in balancing economic and social commitments.

From the five key elements of any logistics processtransport, storage, inventory, information and packaging (Islam et al. 2013) — we have used the first four in this paper to analyze the logistics practices of food banks. On the one hand, transport is the factor with the greatest influence on the logistics process, and storage and inventory are the physical means for the success of such process. On the other hand, information is an intangible factor, linked to all the others, that takes a key role in food banks, especially in the form of awareness-raising campaigns; these campaigns are addressed to transmitting human values in order to improve the connection between demand (beneficiaries) and offer (donors). Finally, we have excluded packaging, taking into account that this activity is not generally a common and/or core factor when talking about food banks that operate as intermediary agents.

In short, the role of a food bank could have a positive impact on both the environment and in society, firstly reducing waste, and secondly giving the potentially wasted food to needy people. But, do all food banks have a similar behavior? As explained in first section, scarce studies in the literature address the study of food banks from the point of view of management. Therefore, that is the gap in the understanding of these particular non-profit organizations that are analyzed in our research. The paper tries to identify a single, common way of functioning or, in case of a possibly negative answer to that question, to identify a reference model for improving the way the rest of the food banks function.

\section{Methods and procedures}

From results of a previous case study in Spain (Coque et al. 2012) and prior literature reviews (see international outlook in second section and questionnaire justification below) we show that the operating results of a food bank are conditioned by the characteristics of the organization and the conditions in which it operates. As we have already mentioned, this research tries to analyze if all the food banks in Spain are virtually similar or if different groups can be identified, based on such characteristics and conditions. Taking into account that we did not have a wide knowledge on the Spanish food banks and that our main purpose was exploring the possible existence of different groups within them, a cluster analysis on a massive amount of survey data seemed to be the most viable approach (see below for more details).

\section{Sample selection}

The target population of this empirical research includes all the food banks located within Spain - a total of 55 banks. Considering that this study also tries to achieve as complete an overview as possible, we considered surveying to be the most appropriate research methodology. As the size of the target population is not too large, the questionnaire was sent to the full population of food banks. The decision of each entity to participate or not in the survey determined the sampling.

Data collection was carried out in 2012, in two phases. The first step was executed in July, prior to the summer holiday period. The second was executed in the period from September to December in order to increase the response rate. Previously, by the end of June, a pre-test had been made to four entities with the purpose of testing and improving the questionnaire. The size of the final sample achieved was 42 food banks, which means a response rate 
of $76.4 \%$. We then tabulated the information achieved from the questionnaire and treated it statistically using cluster analysis to check if the classifying variables allowed the differentiation between different types of food bank in Spain, as suggested by the literature. After that, we made a descriptive analysis of the identified groups that had been validated through discriminant analysis.

\section{Questionnaire}

Based on previous literature reviews (especially those of Cotugna and Beebe 2002; Cotugna et al. 1994; Daponte and Bade 2006; do Paço and Agostinho 2012; Tarasuk and Eakin 2005), the research team discussed a first draft of the questionnaire to arrive at a prototype, improving it by the feedback of experts from the research, whose opinions contributed highly to the final quality. During the pre-test we detected some difficulties, such as barriers to identifying the right contacts and the lack of time to respond by some food banks. Some contact data were not correct in the initially available information. On the other hand, some of the data requested in the questionnaire were not directly available and then collection became time-consuming. Lessons learned from this test were again discussed within the research team and incorporated in the final version of the questionnaire. This process was intended to guarantee the efficacy and consistency of the questionnaire. The final version consisted of 36 questions grouped in seven areas: general data about each entity, bank operation, volunteers, material resources, donators, beneficiaries, and image. The main questions used in that research have been provided in the "Appendix".

We obtained the list of the whole population of food banks from the Spanish Federation of Food Banks (FESBAL). Firstly we contacted each food bank via telephone to explain the aim of the research and to request its participation in completing the questionnaire. After that, we sent the questionnaire by email, except in a couple of cases where it was sent via traditional mail due to their lack of computers. This process was repeated twice, the first time between June and July and the second between September and December 2012. We did not offer any incentive to complete and return the questionnaire.

\section{Classifying variables}

To select the classifying variables, we looked upstream and downstream of the food bank in the supply chain. Upstream, we have the donators (Fig. 1)-corresponding to suppliers in traditional supply chains. Donations may come from different sources: volunteer donations by public or private entities, on the one hand (Johnson and Hawkins 2010), and "kilo operations" (donations of food by individuals and firms through public and private organizations), on the other. Downstream we have the distributing and consuming entities, corresponding to the clients in traditional supply chains (Fig. 1). They could belong to two different types: distribution centers (where batches of food are redistributed among the people and beneficiary groups) and consumption centers (whose users are provided with cooked and prepared food to be consumed on the premises) (Berner and O'Brien 2004).

Taking into account upstream and downstream agents, the classifying variables considered were percentage of public donators and percentage of kilo operations (upstream), and percentage of distribution centers (downstream). On average, $7.5 \%$ of donations came from public entities and a little less than $30 \%$ from kilo operations. Therefore, private contributions are clearly significant. When looking at the different types of distributing entities, the distributing and consuming organizations appeared to be quite balanced, although the quantity is a little lower in the second case than in the first one $(45.3 \%)$.

\section{Method of analysis}

Cluster analysis uses data from different variables to join cases (the food banks) into internally homogeneous groups but differentiates among them (Morgan and Griego 1998). This statistical test is then a good tool to answer our research question. If the classification variables allow to state different groups of food banks attending to their behavior, then different clusters must be obtained as a result. We used the computer software SPSS v.19 to do this. The main reason for carrying out a cluster analysis was then the research question, because we try to identify different types of food banks by looking at their operations. These different groups can help to identify more efficient behaviors that could be copied by the other food banks.

\section{Results}

Before starting the cluster analysis itself, it was necessary to check two prerequisites: the representativeness of the sample and the non-existence of multicollinearity between the variables. The first was guaranteed by the sample size, which is more than $75 \%$ of the target population. To ensure the absence of multicollinearity (or linear relationship) between the classification variables, we carried out an analysis of bivariate correlation, where a coefficient near to 1 shows a strong linear dependence between each pair of variables and a coefficient near to 0 indicates the absence of dependence. These results showed the independence between these variables since the correlation coefficients were not significant (significance level around 0.1). 
Table 3 Descriptive analysis by conglomerates

\begin{tabular}{lcc}
\hline Mean (standard deviation) & Conglomerate 1 (35 cases) & Conglomerate 2 (7 cases) \\
\hline Upstream of the supply chain & & \\
\% Public entity donors & $8.51(9.14)$ & $2.45(2.91)$ \\
\% Private entity donors & $63.79(15.83)$ & $38.19(27.11)$ \\
\% Kilo operations & $23.22(12.94)$ & $59.35(29.60)$ \\
Downstream of the supply chain & & \\
\% Distribution centers beneficiaries & $39.64(20.89)$ & $74.34(17.69)$ \\
\% Consumption centers beneficiaries & $56.51(22.79)$ & $25.66(17.69)$ \\
\hline
\end{tabular}

The number of clusters to obtain is usually determined using the method of hierarchical clusters. Analyzing the dendogram or distance matrix (both of which represent the differences among internally homogeneous groups), we detected the membership of the Spanish food banks in two different clusters with different sizes (Table 3). A new cluster analysis, using the k-means algorithm, confirmed the previous result, which means that our previous decision of estimating two different clusters is appropriate.

The first cluster was composed of 35 food banks, while the second one contained only seven entities. Using a descriptive analysis of clusters (Table 3), the high level of participation of the food banks of cluster 2 in kilo operations is clear. Kilo operations are nearly three times higher in cluster 2 than in cluster 1 , and collaboration with the distribution centers is essential (almost two-thirds of food bank activity is dedicated to this).

To validate the quality of the clusters obtained, we proved the existence of statistically significant differences in the classification variables of both clusters. Previously we carried out a Kolmogorov-Smirnov test to check the normality of the distributions of the classification variables (Table 4, second column). It showed that we must reject the hypothesis that the variable of the percentage of public entities donors (in-kind donations) is normally distributed. Then, as one of the classification variables is not normally distributed, a non-parametric Mann-Whitney test for independent samples checked the equality of the means of the variables. Table 4 (third column) shows that the null hypothesis of similarity in the average of the variables can be rejected only in the cases where variables are related to the kilo operations and the distribution centers. Although the differences in the distribution of the variable on donations of public entities cannot be ensured, the existence of differences in the other two classification variables employed is clear and therefore the cluster analysis carried out is considered to be validated.

To verify the existence of other differences between both clusters obtained with regard to the internal management of the respective food banks, we show in Table 5 all the variables studied, as well as the verification tests of the similarity between the two clusters (we use non-parametric
Table 4 Analysis of normality of the classification variables

\begin{tabular}{llc}
\hline Statistical (significance) & Normality test & $U$ Mann-Whitney test \\
\hline$\%$ Public entities & $1.441(0.031)$ & $74,500(0.103)$ \\
$\%$ Kilo operations & $1.035(0.234)$ & $213,000(0.002)$ \\
$\%$ Distribution centers & $0.511(0.956)$ & $220,000(0.001)$ \\
\hline
\end{tabular}

tests due to the fact that the condition of normality needed for the use of parametric tests of this type does not exist in many cases). There are statistically significant differences in the distribution of daily time to the different activities of each food bank, and in the sources of funding (Table 5). Conglomerate 1 is characterized by spending a large part of the day-to-day in actions in logistics management, while in conglomerate 2 , although the administrative and logistical tasks represent more than half of the working day, the food banks drew particular attention to the effort invested in awareness work. Besides, the first cluster accounts for private entities as the main source of funding (more than $25 \%$ of its financial resources have this origin), while the second cluster receives from the food bank's own partners one-third of the financial resources of the organization.

We performed the corresponding discriminant analysis using the four variables indicated in bold in Table 5 (time spent in logistics management, time spent in awareness tasks, funding by private entities, and funding by partners' quotas), which show statistically significant differences between the two clusters obtained previously. Starting from a set of elements already grouped, this statistical test allows finding linear relationships between the independent variables that best discriminate the pre-set groups (Morgan and Griego 1998). In addition, it enables constructing a decision rule that sets the group ownership of a new item to categorize. This uses the Wilks' Lambda method, where the variables are introduced step by step, incorporating in each of them the variable with the highest Snedecor's F and with less Wilks' Lambda (Table 6). As a final result, the last of the variables in Table 5, the time invested in awareness, is excluded from the model.

With regard to the canonical discriminant functions obtained, the canonical correlation coefficient is 0.694 , indicating that almost $70 \%$ of total variability is due to the 
Table 5 Analysis of other differences between the clusters

\begin{tabular}{|c|c|c|c|}
\hline \multirow[t]{2}{*}{ Variables } & \multicolumn{2}{|c|}{ Descriptive: mean (standard deviation) } & \multirow{2}{*}{$\begin{array}{l}\text { Mann-Whitney: } \\
\text { statistic (sig.) }\end{array}$} \\
\hline & $\begin{array}{l}\text { Conglomerate } 1 \text { "Specialised } \\
\text { food banks" }\end{array}$ & $\begin{array}{l}\text { Conglomerate } 2 \text { "Complete } \\
\text { food banks" }\end{array}$ & \\
\hline Years of operation & $15.56(7.79)$ & $14.56(6.88)$ & $113.500(0.759)=$ \\
\hline \multicolumn{4}{|l|}{ Staff } \\
\hline $\mathrm{N}^{\circ}$ volunteers & $37.41(37.95)$ & $56.71(55.16)$ & $164.000(0.161)=$ \\
\hline $\mathrm{N}^{\circ}$ paid workers & $1.38(1.83)$ & $2.00(2.89)$ & $128.500(0.832)=$ \\
\hline \multicolumn{4}{|l|}{$\%$ Time spent } \\
\hline Administrative management & $22.28(11.90)$ & $28.57(16.51)$ & $157.500(0.179)=$ \\
\hline Logistics management & $60.98(17.09)$ & $37.14(16.80)$ & $35.500(0.003 *) \neq$ \\
\hline Kilo operations & $11.15(13.62)$ & $15.00(7.07)$ & $172.500(0.055)=$ \\
\hline Awareness & $9.56(13.74)$ & $15.00(7.07)$ & $186.000(0.018 *) \neq$ \\
\hline \multicolumn{4}{|l|}{ Collected } \\
\hline Donations (kg) & $1,098,110.55(1,356,526.79)$ & $652,770.00(645,214.24)$ & $88.000(0.244)=$ \\
\hline EU programs $(\mathrm{kg})$ & $891,030.70(750,609.40)$ & $1,110,028.86(992,421.48)$ & $135.000(0.673)=$ \\
\hline \multicolumn{4}{|l|}{ Funding sources } \\
\hline Public entities & $36.02(16.41)$ & $34.00(19.33)$ & $105.000(0.717)=$ \\
\hline Private entities & $26.51(25.21)$ & $1.00(2.24)$ & $40.000(0.018 *) \neq$ \\
\hline Individuals & $18.38(25.41)$ & $23.10(33.80)$ & $98.000(0.879)=$ \\
\hline Members' quotas & $6.81(8.81)$ & $34.80(33.80)$ & $157.500(0.002 *) \neq$ \\
\hline \multicolumn{4}{|l|}{ Volunteers } \\
\hline Years & $58.57(11.47)$ & $55.93(8.66)$ & $98.500(0.417)=$ \\
\hline$\%$ Men & $76.75(20.50)$ & $80.48(17.61)$ & $136.500(0.634)=$ \\
\hline \multicolumn{4}{|l|}{ Material resources } \\
\hline Warehouses $\left(\mathrm{m}^{2}\right)$ & $989.86(651.71)$ & $642.86(680.95)$ & $82.000(0.171)=$ \\
\hline $\mathrm{N}^{\circ}$ transport elements & $2.91(2.31)$ & $2.71(1.50)$ & $130.500(0.781)=$ \\
\hline $\mathrm{N}^{\circ}$ handling elements & $5.23(4.25)$ & $4.00(2.64)$ & $107.500(0.611)=$ \\
\hline \multicolumn{4}{|l|}{$\%$ Collected food } \\
\hline Dairy & $19.22(10.83)$ & $20.14(8.07)$ & $81.000(0.678)=$ \\
\hline Fresh fruit & $14.96(13.15)$ & $11.20(12.16)$ & $62.500(0.626)=$ \\
\hline Fresh vegetables & $10.13(8.62)$ & $10.40(12.39)$ & $64.500(0.695)=$ \\
\hline Fresh fish & $1.34(2.10)$ & $0.54(0.46)$ & $84.500(0.537)=$ \\
\hline Biscuits and pastries & $7.43(5.74)$ & $8.09(6.72)$ & $75.500(0.883)=$ \\
\hline Pasta and rice & $10.19(8.70)$ & $14.53(6.90)$ & $104.500(0.118)=$ \\
\hline
\end{tabular}

Variables in bold present statistically significant differences between two clusters obtained

differences between the two groups. On the other hand, the Wilks' Lambda test, in which the null hypothesis is the equality in the average of the discriminant functions of groups, presents a coefficient of 0.519 with a significance level of 0.000 . This result allowed the rejection of the equality between the two clusters. The Fischer's two discriminant functions we obtained allowed us to classify correctly $94.7 \%$ of the cases.

Next we analyzed the effectiveness and efficiency of both identified groups of food banks. Starting with the effectiveness, there is clearly a greater diversification of the activity in the food banks of cluster 2 . This means that they paid more attention to other activities that are different from logistics. Together with the logistics tasks inherent in this type of entity, the foods banks in cluster 2 also employ part of their efforts to raising awareness. Food banks belonging to cluster 2 we have called "complete food banks" while food banks in cluster 1 are called "specialized food banks."

Finally we used an efficiency ratio through relations output/input. We considered the quantity of managed food per year in tons as output, and the time employed per a volunteer in logistics activities as input. Understanding this measurement unit is relevant in order to understand the results obtained and is a great indicator of the efficiency of the main activity of a food bank, i.e. its logistics activities. 
Table 6 Test for equality of means of the groups

\begin{tabular}{llcc}
\hline Variables & Wilks' Lambda & F & Significance \\
\hline Quotas of partners & 0.699 & 15.518 & 0.000 \\
Donations of private entities & 0.839 & 6.929 & 0.012 \\
Time spent in logistics management & 0.841 & 6.782 & 0.013 \\
Time spent in awareness & 0.988 & 0.453 & 0.505 \\
\hline
\end{tabular}

Cluster 2 is significantly more efficient than the food banks in cluster 1 , because they have over twice the tons of managed food per annual volunteering time (2.9 against 1.4). Previously, in Table 5, we found no statistical differences in the quantities of collected food between both clusters. Volunteers in cluster 2 spend much more time in awareness activities and less time in logistics activities. They are more efficient in the physical movement of food and they also improve the social concern. In other words, volunteers in cluster 2 spent their time better on logistics actions, and therefore these logistics procedures should be imitated by food banks belonging to cluster 1 .

\section{Discussion}

In cluster 1 the number of Spanish food banks is significant (more than $80 \%$ of the sample). They are entities supported mainly by private food donors (more than $60 \%$ of their donations are of this type), although the contribution made by public entities should also be highlighted (their percentages quadruple the data of cluster 2-see Table 3 ). Internally, in both clusters, volunteers are the essential human resource in the activity of the food banks (as previous researchers, such as do Paço and Agostinho 2012, found), although "specialized food banks" have a smaller staff throughout the typology (employers, volunteers, and paid staff). These figures of human resources mean that the logistics management (collection from donors, handling and storage of food, as well as their adequate distribution in time and form to the beneficiary centers) is the fundamental activity of each food bank, in which the food banks of cluster 1 invest more than $60 \%$ of their workday. The lack of enough human resources could be the reason that the food banks in cluster 1 spend far less effort in raising awareness (Table 5).

Along with the human factor, we found a better use of volunteers in "complete food banks," doubling their productivity rates from those of cluster 1 . If one considers any person participating in the activity of the food bank, whether voluntary or paid, the trend is the same. It can also be seen that the volunteers would explain better the efficiency in the logistics tasks of the food bank, because when the calculation introduces the data of paid staff there is less difference in the ratios between the two clusters (from 52 to $40 \%$ ). This may be due to the fact that the few salaried workers are more involved in administrative and management work than in the logistics tasks that are the main activity of the food bank.

Because of the logistics work described above, we note that each "specialized food bank" collected annually an average of more than 1000 tons of food donated by companies and individuals, dropping to $900,000 \mathrm{~kg}$ from the programs of the European Union (Table 5). Nearly one-fifth of these foods are milk, followed by fresh fruit and drinks. These data conflict with other previous studies where the diversity of products distributed differs (Cotugna et al. 1994) and give an idea of the third logistics factor to consider, inventories (Islam et al. 2013), given the amount of food managed. Such discrepancy could be explained by the differences in eating habits among countries and their cultures. Storage and transport to manage these quantities of food are the first and second logistics criteria defined by Islam et al. (2013). Following with cluster 1 , the average surface for storing does not reach $1000 \mathrm{~m}^{2}$, and the available surface for office space is less than $100 \mathrm{~m}^{2}$ (Table 5). Each food bank also has an average of two or three means of transport, and five or six different types of handling equipment.

The main sources of funding for the "specialized food banks" are private entities, followed by public entities at a regional or national level (municipalities collaborate to a lesser extent when one looks at the figures of participation together with cluster 2). It must be borne in mind that the non-profit entities studied have the characteristic of being supported mainly by donations of food, having little or no financial resources (Johnson and Hawkins 2010). This trend is usual in Europe, unlike what happens in North America (Nichols-Casebolt and Morris 2001) or in South Africa (Foodbank South Africa 2013).

With regard to the profile of volunteering, there are no differences between the two identified clusters. In both cases, the average age is over 55 years, and the presence of retired men and with some kind of study qualification, mainly secondary, is extended.

To highlight some peculiarities of the cluster 1 volunteers, we must pay attention to the participation of housewives (slightly more than $8 \%$ ), as well as the fact that almost $20 \%$ of the volunteers have only primary education. In any case, the gender of the volunteer of food banks is usually masculine; these data collide with the predominance of women as volunteers in other types of nonprofit entities (Franco Rebollar and Girard 2011). 
With regard to cluster 2 , unlike cluster 1 , the kilo operations are more usual. These actions account for almost $60 \%$ of the food collection of these entities (Table 3). The social product offered by cluster 2 is more complete, due to the fact that a great part of kilo operations is prepared for attending to a particular social need and these food banks therefore better achieve their social goals.

Again, the whole activity of a food bank can be carried out thanks to the participation of selfless volunteers. Although they spend much of their time and effort either working in logistics, management or administrative tasks, they also pay special attention to awareness, in the case of cluster 2 , which means a greater amount of kilo operations is carried out (Table 3). Likewise, they receive larger amounts of food from EU plans (Table 5), which involves a more bureaucratic burden but lower logistics work. Besides, the productivity ratios of the human resources reveal a greater efficiency in cluster 2. For this reason, speaking in average terms and in relation to cluster 1, these "complete food banks" have smaller warehouses and larger spaces to be used for offices, as well as fewer amounts of handling equipment and more computer equipment.

There are also differences in the beneficiaries of the food banks between both clusters. Complete food banks essentially serve distribution centers (almost $75 \%$ of the cases-Table 3). In addition, dairy is again the food mostly distributed by the food banks of cluster 2 (following the European tendency where the largest collected product group is dairy-Schneider 2013), but followed on this occasion by pasta and rice (Table 5). This last group of food has also been one of those most distributed in food banks of other countries, as Cotugna et al. (1994) already showed at the end of the last century.

\section{Conclusions}

After having pointed out the relevance of the differences between several countries, particularly with regard to the size of the networks of the food banks available and the profile and number of their beneficiaries, this research carried out in Spain has allowed us to test the existence of two different types of food bank in response to the relationship they have, both up and down, within the supply chain; that is to say, Spanish food banks have been classified depending on their ties with their suppliers, in this case the donor entities, and with their customers, the beneficiary organizations. The verification of such a dichotomy is our first contribution to the general knowledge within the non-profit sector field.

We have covered a second gap by means of our conceptual approach, which combines the classic management studies on the supply chain with topics related to non-profit entities, i.e. the sector to which food banks belong. In the literature review there was a clear lack of research from such a point of view. The first part of approach pays attention to factors such as transport, storage, inventory, and information; the second part deals with voluntary staff, income from selfless sources, and a solidarity network.

As a third innovation, we have described the respective profiles of both clusters in order to highlight the features of the most successful food banks, which could suggest ways of improvement to other food banks.

In the first cluster there is the largest number of cases, whose profile would be the most widespread throughout the national territory. They are entities that focus their efforts on logistics activities, with no remaining time or other resources for other tasks such as awareness campaigns, which could improve their logistics results and provide a greater comprehension of their social product. The reason for this decision could be found in the reduced availability of staff (both workers and volunteers) at all hierarchical levels of each organization. Their main funding source is private. Upstream in the supply chain, most of the received donations are also private. Downstream, its main beneficiaries are consumption centers.

A second cluster of food banks is composed of only seven entities, which present differentiating features from generality. They focus their efforts equally on administrative and logistical tasks, but with a greater emphasis on the awareness tasks and kilo operations; these two last actions are particularly interrelated and enhance the social concern for the hungry. We must point out here that their main funding source comes from the partners themselves, which gives them greater stability. Upstream, most of the donors come from kilo operations, while, downstream, distribution centers are their main beneficiaries. This may be due to the fact that the demand of these centers is more heterogeneous and fluctuating than in the consumption centers, which requires a greater capacity for management. The food banks belonging to the second cluster are more flexible in their management when compared with those of cluster 1 , and can better meet the specific needs of the distribution centers, due to the fact that they can organize kilo operations for recovering food to cover a particular social need for food. Indeed, we have verified (by interviews with staff in charge of the food bank studied) that distribution centers have raised more than consumption centers over the recent socioeconomically crisis years; so, second cluster food banks are answering more precisely to their environment's needs. Their operation is therefore more effective and efficient in all fields. With respect to efficiency, we cannot forget that the management field of the traditional supply chain has usually devoted its studies to costs (Sezen 2008), which is especially important in food banks - in the non-profit sector in general-when we realize the resource shortages with which they have to work. 
In the final analysis, the first type of cluster is characterized by smaller entities whose scarce human resources are concentrated-probably from being too short-term and at an accelerated pace-on fulfilling the food bank's primary purpose: collecting and distributing food. In the second type of cluster, a small number of larger organizations with more resources and a strategic overview are observed, allowing them to offer a more comprehensive social product that includes social awareness. This action could put in doubt some of the criticism that food banks often receive, i.e., that they could actually cause chronic social demands to alleviate hunger, which could justify the public sector's inaction in trying to meet such demands (Daponte and Bade 2006). ${ }^{1}$ Therefore, it could be concluded that the food banks of the second cluster are the "leaders" in their activity, serving as reference models or examples to the entities belonging to the first cluster of "followers." We believe the system of food redistribution is better (more complete and interconnected) when human values are enhanced. This is the case of the complete food banks, where special attention is paid to the awareness tasks, as compared to the entities of cluster 1, which are also concerned in the movement and management of food. As Dixon (2014) states by means of describing several cases of nourishment self-help in the US, sharing information on both hungry causes and solutions is a key measure to advance towards food justice.

Such dichotomy corresponds with the more general overview of the Spanish non-profit entities, which is in spite of a huge heterogeneity that makes their study as a whole difficult (Ariño Villarroya 2008). Most of the Spanish non-profit entities are small organizations and quite specialized, while the rest are large, complex, and usually diversified entities that, paradoxically, tend to be best known by occupying more space in the media.

\footnotetext{
${ }^{1}$ Beyond this consideration, we cannot deny criticisms, or direct attacks, that food banks frequently receive for limiting themselves to solving a short term social need, i.e., the lack of food at home, and not eradicating the problem at its source, i.e. hunger and poverty around the world, declining the role of governments in addressing these social requirements. For example, "Food Banks should not be seen as a 'normal' part of a national safety net. They are charity-based, not rights-based, and they should not be seen as a substitute for the robust social safety nets to which each individual has a right $[\ldots]$ Governments should not be allowed to escape their obligations because private charities make up for their failures" (statement by Olivier De Schutter, Special Rapporteur for the United Nations, in New Mexico, July of 2014). Although we agree essentially with these approaches, by means of this research we also recognize the important temporary role that food banks play for wider sectors of poor people. Therefore, analyzing the daily activity of food banks and their relationship up and downstream in their supply chain in order to improve it would be useful at the moment. And, as we indicate in these conclusions, the more complete offer of cluster 2 food banks, that includes social awareness, would better fight the whole problem (i.e., the actual problem).
}

In addition, in this work, we have studied the resources that are within each food bank (human, material, and financial), and their results (quantities of food collected and distributed, and their typology). Taking into account the human resources in particular, and given the average age of volunteers, which is the main work factor in this type of non-profit entity, we feel it would be advisable to promote the recruitment of younger people sensitized to the aim of food banks. These new volunteers could supplement perfectly the work experience gained over the years by the current, older volunteers. This rejuvenation of the staff would allow a better distribution of tasks, which in many cases requires specific knowledge of new information technologies (such as Evans and Clark 2010, point out). This would enhance the internal and external coordination of each food bank, which would improve their performance.

Since there are clear differences in the relationships between food banks of both clusters identified with the predecessors and successive links of their supply chain, future extensions of this research work will seek to address in greater depth, on the one hand, the beneficiaries, distinguishing between distribution centers and consumption centers, and, on the other hand, studies of donor organizations. We have identified other several interesting areas for future research related to resources shortages (food, money, labor), managing volunteers, or type and quality of goods handled. These ideas point to new lines of work to continue the research in this field. Moreover, our work has been limited to studying the differences and similarities of food banks within one specific country, Spain; subsequent studies could extend the research to other countries to establish comparisons within the European Union, or of its reality versus similar situations in other continents.

Acknowledgments This study was funded by the Ministry of Economy and Finance DPI2013-41469-P and the European Regional Development Fund (ERDF). It also benefited from a grant provided by the City of Gijón through the University Institute of Industrial Technology of Asturias (IUTA) (project SV-14-GIJÓN-1).

Open Access This article is distributed under the terms of the Creative Commons Attribution License which permits any use, distribution, and reproduction in any medium, provided the original author(s) and the source are credited.

\section{Appendix: Main questions of the questionnaire}

1. Year of food bank's foundation:

2. Please, indicate the number of people in each case: Volunteers _, Paid workers

3. Every day in the food bank, how much time is spent on the following actions? 
Administrative management

Logistics management

Kilo operations

Awareness

4. What quantities of food are received from...?

Donation _ kg/year, EU programs _ $\mathrm{kg} /$ year

5. Kind of food managed:

\begin{tabular}{lc}
\hline Drinks & $\%$ \\
Dairy & $\%$ \\
Fresh fruit & $\%$ \\
Fresh vegetables & $\%$ \\
Fresh fish & $\%$ \\
Pulses & $\%$ \\
Biscuits and pastries & $\%$ \\
Pasta and rice & $\%$ \\
Cheese & $\%$ \\
\hline
\end{tabular}

6. The main funding sources of the food bank are:

\begin{tabular}{lc}
\hline Public entities & $\%$ \\
Private entities & $\%$ \\
Individuals & $\%$ \\
Partners' quotas & $\%$ \\
\hline
\end{tabular}

7. About the volunteers:

Average _years old and _ \% men

8. About materials resources:

__square meters for warehouses, _ _ transport elements, _ handling elements

9. How many donors does the food bank have? _ public entity donors, _ private donors, _ entities collaborating with kilo operations

10. How many centers' beneficiaries does the food bank have?

_ consumption centers' beneficiaries, __distribution centers' beneficiaries

\section{References}

Alexandre, C., and C. Smaje. 2008. Surplus retail food redistribution: an analysis of a third sector model. Resources, Conservation and Recycling 52(11): 1290-1298.

Ariño Villarroya, A. 2008. Articulación del tercer sector en España. Revista Española del Tercer Sector 10: 107-129.

Berner, M., and K. O'Brien. 2004. The shifting pattern of food security support; food stamp and food bank usage in North
California. Nonprofit and Voluntary Sector Quarterly 33: 655-672.

Cai, X., J. Chen, Y. Xiao, X. Xu, and G. Yu. 2013. Fresh-product supply chain management with logistics outsourcing. Omega 41: 752-765.

Coque, J., P.L. González-Torre, and C. Torres. 2012. Los bancos de alimentos: Estudio de un caso en España. VII Congreso RULESCOOP "Economía social: identidad, desafíos y estrategias," 5-7 September. Valencia, Spain: Congreso Internacional Rulescoop.

Cotugna, N., and P.D. Beebe. 2002. Food banking in the 21st century: much more than a canned handout. Journal of the American Dietetic Association 102(10): 1386-1388.

Cotugna, N., C.E. Vickery, and M. Glick. 1994. An outcome evaluation of a food bank program. Journal of the American Dietetic Association 94(8): 888-890.

Daponte, B.O., and S. Bade. 2006. How the private food assistance network evolved: interactions between public and private responses to hunger. Nonprofit and Voluntary Sector Quarterly 35(4): 668-690.

Dixon, B.A. 2014. Learning to see food justice. Agriculture and Human Values 31(2): 175-184.

do Paço, A.M.F., and D. Agostinho. 2012. Does the kind of bond matter? The case of food bank volunteer. International Review on Public and Nonprofit Marketing 9(2): 105-118.

Egri, P., and J. Váncza. 2013. A distributed coordination mechanism for supply networks with asymmetric information. European Journal of Operational Research 226: 452-460.

Evans, S.H., and P. Clark. 2010. Training volunteers to run information technologies. A case study of effectiveness at community food pantries. Nonprofit and Voluntary Sector Quarterly 39(3): 524-535.

FAO (Food and Agriculture Organization of the United Nations). 2011. Food loss reduction strategy. Rome: FAO.

FEBA (Federación Europea de Bancos de Alimentos). 2014. http:// www.eurofuudbank.org. Accessed 21 May 2014.

Feeding America. 2013. http://www.feedingamerica.org. Accessed 27 Feb 2013.

FESBAL (Federación Española de Bancos de Alimentos). 2014. http://www.fesbal.org. Accessed 21 May 2014.

Food Banks Canada. 2014. http://www.foodbankscanada.ca/. Accessed 29 Sept 2014.

Foodbank South Africa. 2013. http://www.foodbank.org.za/. Accessed 19 Feb 2013.

Franco Rebollar, P., and C.I.G. Girard. 2011. Situación y tendencias actuales del voluntariado de acción social de España. Documentación Social 160: 15-41.

Godfray, H.C.J., I.R. Crute, L. Haddad, D. Lawrence, J.F. Muir, N. Nisbett, J. Pretty, S. Robinson, C. Toulmin, and R. Whiteley. 2010. The future of the global food system. Philosophical Transactions of the Royal Society B 365: 2769-2777.

Handforth, B., M. Hennink, and M.B. Schwartz. 2013. A qualitative study of nutrition-based initiatives at selected food banks in the feeding America network. Journal of the Academy of Nutrition and Dietetics 113(3): 411-415.

Hodges, R.J., J.C. Buzby, and B. Bennett. 2011. Postharvest losses and waste in developed and less developed countries: opportunities to improve resource use. Journal of Agricultural Science 149: 37-45.

INE (Instituto Nacional de Estadística). 2013. Encuesta de Condiciones de Vida. Madrid, Spain: Instituto Nacional de Estadística.

INE (Instituto Nacional de Estadística). 2014. Instituto Nacional de Estadística. http://www.ine.es. Accessed 1 Oct 2014.

Irwin, J.D., V.K. Ng, T.J. Rush, C. Nguyen, and M. He. 2007. Can food banks sustain nutrient requirements? A case study in 
Southwestern Ontario. Canadian Journal of Public Health 98(1): $17-20$.

Islam, D.M., J.F. Meier, P.T. Aditjandra, T.H. Zunder, and G. Pace. 2013. Logistics and supply chain management. Research in Transportation Economics 41: 3-16.

Johnson, S., and N. Hawkins. 2010. Calcium nutrition perception among food bank users: a Canadian case study. International Electronic Journal of Health Education 13: 100-110.

Kantor, L.S., K. Lipton, A. Manchester, and V. Oliveira. 1997. Estimating and addressing America's food losses. Food Review 20(1): $2-12$.

Lambie-Mumford, H. 2013. "Every town should have one": emergency food banking in the UK. Journal of Social Policy 42(1): 73-89.

Larson, P.D., and R. McLachlin. 2011. Supply chain integration under chaotic conditions: not-for-profit food distribution. International Journal of Procurement Management 4(3): 315-322.

Magrama. 2013. Estrategia "Más alimento, menos desperdicio." Programa para la reducción de las pérdidas y el desperdicio alimentario y la valorización de los alimentos desechados. Madrid, Spain: Ministerio de Agricultura, Alimentación y Medio Ambiente.

Martins, I., T. Guedes, P. Rama, J. Ramnos, and T. Tchemisova. 2011. Modelling the problem of food distribution by the Portuguese food banks. International Journal of Mathematical Modelling and Numerical Optimisation 2(3): 313-341.

McIntyre, L. 2003. Food security: more than a determinant of health. Options Politiques. pp. 46-51.

Mena, C., B. Adenso-Díaz, and O. Yurt. 2011. The causes of food waste in the supplier-retailer interface: Evidences from the UK and Spain. Resources, Conservation and Recycling 55(6): 648-658.

Morgan, G.A., and O.V. Griego. 1998. Easy use and interpretation of SPSS for Windows. New Jersey: Lawrence Erlbaum Associates.

Nichols-Casebolt, A., and P. Morris. 2001. Making ends meets: private food assistance and the working poor. University of Wisconsin, Institute for Research on Poverty research paper no. 1222-01. Madison, WI: University of Wisconsin, Institute for Research on Poverty.

Pothukuchi, K., and J.L. Kaufman. 1999. Placing the food system on the urban agenda: The role of municipal institutional in food systems planning. Agriculture and Human Values 16(2): 213-224.
Rajan, A., R. Steinberg, and R. Steinberg. 1992. Dynamic pricing and ordering decisions by a monopolist. Management Science 38(2): 240-262.

Schneider, F. 2013. The evolution of food donation with respect to waste prevention. Waste Management 33(3): 755-763.

Sezen, B. 2008. Relative effects of design, integration and information sharing on supply chain performance. Supply Chain Management: An International Journal 13(3): 233-240.

Starkey, L.J., K. Gray-Donald, and H.V. Kuhnlein. 1999. Nutrient intake of food bank users is related to frequency of food bank use, household size, smoking, education, and country of birth. The Journal of Nutrition 129(4): 883-889.

Starkey, L.J., H.V. Kuhnlein, and K. Gray-Donald. 1998. Food bank users: sociodemographic and nutritional characteristics. Canadian Medical Association Journal 158(9): 1143-1149.

Tarasuk, V., and J.M. Eakin. 2005. Food assistance through "surplus" food: insights from an ethnographic study of food bank work. Agriculture and Human Values 22(2): 177-186.

The Trussell Trust. 2013. http://www.trusselltrust.org/foodbankprojects. Accessed 21 Feb 2013.

United Nations. 2011. Millennium development goals. Inform no.S.11.I.10. New York: UN.

Warshawsky, D.N. 2011. Food bank Johannesburg, state, and civil society organizations in post-apartheid Johannesburg. Journal of Southern African Studies 37(4): 809-829.

Yadlowski, L., and L. Thériault. 1998. Food banks in Canada: a review of literature. University of Regina working paper no. 13. Regina, Canada: University of Regina.

Pilar L. González-Torre, Ph.D. is an Industrial Engineer and Associate Professor of Business Management at the Engineering School of the University of Oviedo, Spain. She is the author of a book on reverse logistics and has published several articles in scientific journals about reverse logistics and environmental management, among other issues.

Jorge Coque, Ph.D. is an Industrial Engineer and is currently an Associate Professor of Business Management at the Engineering School of the University of Oviedo, Spain. His research centers on issues of social economy (cooperatives and nonprofit organizations), entrepreneurship, and cooperation for development. 